\title{
CAPITAL SOCIAL EM UM CONSÓRCIO DE PESQUISA
}

\section{SOCIAL CAPITAL IN A RESEARCH CONSORTIUM}

CAPITAL SOCIAL EN UN CONSORCIO DE INVESTIGACIÓN

\begin{abstract}
RESUMO
Capital social é discutido no âmbito do Consórcio Brasileiro de Pesquisa e Desenvolvimento de Café. O objetivo é investigar a viabilidade de utilizar o capital social como instrumento para explicar o gradiente de recursos do consórcio de que os pesquisadores conseguem se apropriar para seus projetos de pesquisa. Foi desenvolvida e aplicada uma métrica de capital social para testar a existência de correlação entre volume de recursos captado e volume de capital social. A análise sociométrica de escolhas preferenciais dos pesquisadores e a quantificação da participação desses cientistas em projetos do consórcio permitiram o cômputo de uma grandeza - capital social - que poderia vir a explicar metade da variação da verba obtida pelos cientistas responsáveis por projetos de pesquisa na rede.
\end{abstract}

PALAVRAS-CHAVE Capital social, rede colaborativa, consórcio de pesquisa, análise de redes sociais, pesquisa de café.

Uajara Pessoa Araújo uajara@yahoo.com.br

Professor do Departamento de Ciências Sociais Aplicadas, Centro Federal de Educação Tecnológica de Minas Gerais - Belo Horizonte, MG, Brasil

Luiz Marcelo Antonialli Imantonialli@uol.com.br

Professor do Departamento de Administração e Economia, Universidade Federal de Lavras - Lavras - MG, Brasil

Mozar J. de Brito mozarjdb@ufla.br

Professor do Departamento de Administração e Economia, Universidade Federal de Lavras - Lavras - MG, Brasil

Fábio Müller Guerrini guerrini@sc.usp.br

Professor do Departamento de Engenharia de Produção, Universidade de São Paulo - São Carlos - SP, Brasil

Recebido em 07.04.2010. Aprovado em 18.10.2010

Avaliado pelo sistema double blind review

Editor Científico: Maurício C. Serafim

\begin{abstract}
We discuss social capital within the scope of the Brazilian Consortium for Research and Development of Coffee. The goal is to test the hypothesis that researchers' social capital may be taken as a variable for the resources of the consortium that these researchers were able to secure in their research projects. It was necessary to develop a social capital metric, apply it, and verify the correlation between the volume of captured resources and the volume of social capital. The application of the network analysis in view of the researchers' preferential choice and the quantification of the participation of these scientists in projects of the consortium enabled an estimation of a magnitude - the social capital - which could explain half the amount of variation obtained by each of the scientists responsible for research projects in the network.
\end{abstract}

KEYWORDS Social capital, collaborative network, research consortium, social network analysis, coffee research.

RESUMEN El capital social es discutido en el ámbito del Consorcio Brasileño de Investigación y Desarrollo del Café. El objetivo es investigar la viabilidad de utilizar el capital social como instrumento para explicar el gradiente de recursos del consorcio del cual los investigadores consiguen apropiarse para sus proyectos de investigación. Fue desarrollada y aplicada una métrica de capital social para testear la existencia de correlación entre volumen captado de recursos y volumen de capital social. El análisis sociométrico de opciones preferenciales de los investigadores y la cuantificación de la participación de esos científicos en proyectos del consorcio permitieron el cómputo de una magnitud - capital social - que podría explicar mitad de la variación del presupuesto obtenido por los cientificos responsables por proyectos de investigación en la red.

PALABRAS CLAVE Capital social, red colaborativa, consorcio de investigación, análisis de redes sociales, investigación del café. 


\section{INTRODUÇÃO}

O Brasil vem aumentando a sua participação na produção de conhecimento, persistindo em uma tendência positiva acentuada a partir da segunda metade da década 1990. Ciências agrárias é a área de conhecimento em que o Brasil tem presença mais significativa, o que é coerente com a forte orientação agrícola do país, onde o café pode ser destacado. O país tem sido tradicionalmente o maior produtor e exportador de café, mas admite-se que dependerá cada vez mais de tecnologia para fazer frente aos concorrentes e aos desafios representados pela adaptação às condições climáticas e às demandas do mercado.

Desde 1997, o Consórcio Brasileiro de Pesquisa e Desenvolvimento do Café - CBP\&D/Café - tem sido encarregado de conduzir as pesquisas sobre a cultura, canalizando, nos 10 anos estudados, algo próximo a 110 milhões de dólares em recursos diretos, oriundos de um fundo constituído de taxas cobradas dos produtores de café e administrado pelo Conselho Deliberativo de Política de Café, CDPC. Quando acrescida a contraparte suprida pelas entidades consorciadas, o valor aplicado na pesquisa de café resulta superior a meio bilhão de dólares.

No período, de acordo com o banco de dados da Empresa Brasileira de Pesquisa Agropecuária (Embrapa), entidade coordenadora do consórcio, foram executados 889 projetos, por equipes que montaram a 1.500 pesquisadores, de 48 entidades. Esses projetos compuseram os planos anuais, que representam o resultado de decisões oriundas de comitês de pesquisas de núcleos temáticos do consórcio, compostos pelos próprios pesquisadores - que assim participam, propondo, avaliando e executando projetos de pesquisa. Um subproduto de tais ações foi a estruturação de uma rede informal de pesquisadores.

Destarte, o arranjo de pesquisa do café no Brasil teria dois componentes básicos: (1) o CBP\&D/Café, que atuaria como uma agência burocrática, definindo linhas de pesquisas, cooptando, alocando e controlando a aplicação de recursos, divulgando e disciplinando a apropriação dos resultados da pesquisa e, ao mesmo tempo, congregando as principais entidades de pesquisa de café em seus órgãos deliberativos e operacionais; e (2) a rede informal dos pesquisadores de café. Nesse arranjo, o consórcio intenta mediar o encontro da demanda de pesquisa (oriunda do CDPC) e a sua oferta (rede de pesquisadores).

Apesar de, até o momento da pesquisa, não se ter constituído em pessoa jurídica, o consórcio tem caráter formal e legal. As entidades consorciadas participam do conselho diretor e, através de seus pesquisadores, do órgão execu- tivo e dos comitês de pesquisa especializados. O modelo é tal que os pesquisadores atuam na proposição de linhas de pesquisa a atender as demandas do setor produtivo; na indicação das pesquisas merecedoras de financiamento e na condução das pesquisas: ao mesmo tempo em que participam da estrutura do CBP\&D/Café, os pesquisadores competem pelos recursos, submetendo propostas em projetos constituídos por duas a seis unidades (subprojetos), visando resolver um dado problema de pesquisa inscrito entre as linhas de pesquisas favorecidas por edital. Cada unidade é de responsabilidade de uma equipe de uma única entidade, mas o projeto deve ser composto de unidades de pelo menos duas entidades distintas. Portanto, os pesquisadores são instados a se constituírem em equipes e essas equipes são obrigadas a buscar parcerias além das suas respectivas entidades.

As propostas são julgadas por sucessivas instâncias, com participação de elementos da própria rede de pesquisadores, até a sua aprovação final pelo CDPC. Apesar de o julgamento se voltar para o mérito de cada proposta em atender questões prioritárias e para a capacidade dos proponentes em executá-lo, admitir-se-á que é possível a atuação de outros mecanismos que afetam a seleção meramente meritocrática, destacando-se a atuação nada desprezível do capital social dos pesquisadores como variável explicativa da distribuição de verbas do consórcio, no que se constitui o tema da pesquisa, que tem como objetivo principal avaliar tal efeito "perturbador" do capital social na seleção de projetos de pesquisa, no âmbito do CBP\&D/Café.

Para testar essa eventual implicação do capital social, considerou-se necessário apresentar inicialmente algumas contribuições teóricas e empíricas referentes a redes colaborativas, com o objetivo de atestar a validade dos métodos sociométricos e bibliométricos. A revisão da literatura é complementada, discutindo se e como capital social pode ser medido em decorrência da definição adotada para o construto. De antemão, adianta-se que, para esta pesquisa, foi adotado o conceito de capital social de Lin (1999), tido por investimentos de um agente em relações sociais com o propósito de acesso aos recursos do grupo, que podem incluir bens materiais (como verbas de pesquisa), acesso privilegiado a informações, poder (assento nas instâncias decisórias) e mesmo bem-estar decorrente do pertencimento ao grupo.

A seção seguinte, Métodos, já traz o modelo de mensuração e as técnicas empregadas, onde se constata o caráter quantitativo deste que é um estudo de caso, que segue a lógica hipotético-dedutiva, de tal forma que os resultados são confrontados com as hipóteses de pesquisa e se 
discutem algumas considerações adicionais, na última seção do artigo.

A relevância da investigação se dá na medida em que as redes colaborativas se consolidam como arranjo preferencial de pesquisa e passam a demandar maior entendimento. A oportunidade da pesquisa baseia-se na lacuna de trabalhos que envolvam medidas objetivas de capital social, tomado como construto na ordem do indivíduo, para a investigação de redes públicas de pesquisas.

\section{FUNDAMENTAÇÃo}

$\mathrm{Na}$ época da pesquisa, não foram encontrados trabalhos empíricos e quantitativos que propusessem o desenvolvimento de fórmulas específicas de se medir capital social em redes colaborativas de pesquisa assemelhadas ao consórcio. Mas, admitindo-se a existência de capital social, tal como discutido nesta revisão, é também razoável admitir que não haveria impedimento em se buscar a quantificação do capital social em uma rede de pesquisadores, tal como aquela em estudo. O embasamento dessa proposta é apresentado a seguir.

\section{Redes colaborativas}

Para efeito deste trabalho, rede colaborativa de pesquisa é tida como um arranjo caracterizado pelo foco na criação e transferência de tecnologia e pela presença de entes e de financiamento públicos. Dentro desse escopo, as redes colaborativas seriam caracterizadas como predominantemente acadêmicas e sujeitas à regulação informal (em oposição à natureza contratual típica em arranjos privados).

Como têm motivação científica e são premidas pelo imperativo de divulgação de seus resultados através de artigos em periódicos especializados, as redes colaborativas são tomadas como objeto de estudo da bibliometria, utilizada para estudar a evolução de campos do saber e apropriadas em estudos sobre a sociologia da ciência, sobre gestão de $\mathrm{P} \& \mathrm{D}$ e sobre políticas públicas de $\mathrm{P} \& \mathrm{D}$. O material de partida dessas pesquisas são as coautorias e as cadeias de citação. Esses dados servem como indicação da colaboração, promotora da rede de pesquisa.

$\mathrm{Na}$ literatura internacional, as redes colaborativas podem tomar a forma de centros de pesquisas derivados de programas de pesquisas. Como tal, foram motivos de análise os centros ligados ao National Cooperative Program in Infertility Research (CORLEY, BOARDMAN e BOZEMAN, 2006). Ou Centros de Pesquisas focados em biotecnologia e ligados ao National Science Foundation (BOARDMAN e CORLEY, 2008). Mas as redes podem ter um caráter mais difuso, como aferido em redes de coautorias em matemática e neurociência (BARABÁSI e outros, 2002). Dentre tais limites, seria aceitável admitir que as características do arranjo de pesquisa de café no Brasil inscrevem-no mais próximo ao primeiro grupo: uma rede submetida a um grau considerável de deliberação.

As pesquisas sobre redes colaborativas amiúde recorrem a modelos matemáticos sofisticados e a análise estatística, como em Barabási e outros (2002), Landry e Amara (1998), Newman $(2001,2004)$ e Rigby e Edler (2005). Esse tipo de estudo tem comprovado que: (1) um pequeno número de cientistas responde por uma grande parcela de artigos; (2) um pequeno número de pesquisadores tem um grande número de parceiros, enquanto a maioria tem um número significativamente menor; (3) normalmente, é pequena a distância média entre os pesquisadores, medida pelo número de ligações necessárias para ir de um ponto a outro da rede; (4) o menor caminho entre dois pontos da rede normalmente passa por alguns poucos pesquisadores "mais bem" conectados; (5) a maior parte dos pesquisadores está de alguma forma conectada entre si; e (6) as redes são distintas dependendo do campo - em biotecnologia, grandes grupos de muitos pesquisadores, em oposição à matemática, onde os trabalhos são mais individuais e os pesquisadores têm poucos parceiros (NEWMAN, 2001, 2004).

Caberia de antemão antecipar aqui que tais constatações serviram de ponto de partida para o entendimento da distribuição do capital social na pesquisa de café no Brasil: a predominância de pesquisadores estrelas em um arranjo com considerável grau de coesão.

É recorrente em estudos sobre redes colaborativas de pesquisa ligar esse modelo de governança à crença de que as entidades de pesquisas são repositórios de conhecimentos insuficientemente explorados. Uma eficiência maior seria obtida mediante a indução de ligações entre os cientistas, através de exigências de multiinstitucionalidade e de transdisciplinaridade nos financiamentos públicos (RIGBY e EDLER, 2005; CORLEY, BOARDMAN e BOZEMAN, 2006; KATZ e MARTIN, 1997).

Em algum grau, essas pesquisas prévias antecipam o entendimento do arranjo da pesquisa do café, na justaposição de um arranjo burocrático (o CBP\&D/Café) e de uma rede informal, mas induzida, de pesquisadores que ocupam espaços na estrutura burocrática, dinamicamente competindo e colaborando por recursos: não apenas o financiamento de projetos, mas também status e reconhecimento, bem como poder e legitimidade para definir os rumos da própria rede, ao mesmo tempo estável - as ligações têm explicações históricas (NEWMAN, 2001, 
2004) - e fugidia, com limites suficientemente porosos para novas acomodações (BARABÁSI e outros, 2002).

Outro aspecto proeminente no trato dessas redes é endereçar a questão da colaboração em si. Nas pesquisas sobre redes colaborativas, colaboração geralmente é inferida através de coautoria: publicar juntos é o resultado de trabalharem juntos - ainda que isso seja sujeito a diversas considerações, como em Katz e Martin (1997). Rigby e Edler (2005) comprovaram que o aumento do nível de colaboração está fortemente associado com a diminuição da variabilidade da qualidade da pesquisa dentro de certa rede - mas reconhecem que nem sempre os artigos de maior impacto são obtidos de colaboração ou de transdisciplinaridade. Corley, Boardman e Bozeman (2006) afirmam ter demonstrado que a colaboração depende do desenvolvimento epistemológico das disciplinas envolvidas no arranjo. Proximidade espacial e cultural entre cientistas tem efeito positivo sobre a colaboração (LANDRY e AMARA, 1998), bem como existiria correlação entre o volume de verbas amealhado pelo pesquisador, a quantidade de seus parceiros e o grau de abertura a associações mais externas (BOARDMAN e COLEY, 2008, BOZEMAN e CORLEY, 2004).

Bozeman e Corley (2004) criaram uma lista de razões para a colaboração. Ela adviria da necessidade: (1) de acesso a conhecimento, (2) de acesso a equipamentos e a recursos, (3) de encorajar fertilização cruzada através das disciplinas, (4) de acesso a fundos, (5) de se obter visibilidade ou prestígio, (6) de adquirir conhecimento tácito sobre uma técnica, (7) de aumentar a produtividade, (8) de ajuntar conhecimentos para resolver um problema complexo, (9) de educar um aluno, (10) de aumentar a especialização da ciência e (11) por divertimento ou por prazer. Landry e Amara (1998) acrescentam ainda o desejo de (12) aumentar o número de publicações, (13) aumentar o número de inovações, (14) melhorar a qualidade do ensino, (15) aumentar as chances de empregabilidade dos estudantes e (16) construir uma rede de colaboradores. E finalmente, Merlin (2000, p. 39) reconhece que há alto grau de pragmatismo e de personalismo na colaboração: "quando há alguma coisa para ganhar, então uma dada colaboração irá ocorrer; caso contrário - não. Comumente, estará presente alguma química pessoal, e mesmo amizade".

Cabe aqui afiançar que não foram encontradas evidências ao longo da fase empírica dessa investigação de que os pesquisadores brasileiros de café se constituam em espécie à parte - pelo contrário, as explicações colhidas junto a eles de suas ligações e a dinâmica destas ligações corroboram o inventário de Bozeman e Corley (2004) e
Landry e Amara (1998), o que obviamente repercute no arranjo da rede e na distribuição do capital social dos pesquisadores.

\section{Capital social}

Capital Social existe? Ou, mais apropriadamente, qual é a sua validade na explicação de fenômenos sociais? E, afinal, que é o capital social? Como ele pode ser medido? De onde se derivou o modelo utilizado para sua mensuração no arranjo da pesquisa de café no Brasil? Estas são as questões endereçadas a seguir.

De acordo com Batt (2008), a primeira evidência conhecida do emprego do construto capital social remete a L. J. Hafinan, em 1916. Contudo, a difusão de seu emprego é mais recente. Atualmente, capital social tem sido empregado em pesquisas relativas a pobreza e exclusão social (CATTELL, 2001), desenvolvimento (CHIESI, 2007; FARREL e KNIGHT, 2003; KRISNA, 2004), satisfação de indivíduos (GROOT, VAN DEN BRINK e VAN PRAAG, 2007), estudos comparados entre países (VAN OORSCHOT, ARTS e GELISSEN, 2006) e entre comunidades (ONYX e BULLEN, 2000), ecologia (KRAMER, 2007), aprendizagem (GOPEE, 2002) e até criminologia: assassinatos com arma de fogo foram encontrados com correlação negativa frente ao capital social (KENNEDY e outros,1998).

Também digno de nota é o emprego de capital social como variável explicativa em epidemiologia e em saúde (BANKSTON III e ZHOU, 2002; MANSYUR e outros, 2008). Em uma pesquisa representativa dessa linha de pesquisa, foi medido o capital social de 39 estados do EUA, ponderando respostas para dois itens de um questionário: (1) densidade per capita de associados em grupos voluntários, como igreja, sindicatos, associações de bairro; e (2) nível de confiança social: proporção de indivíduos que acreditam que as pessoas são confiáveis. Comprovou-se forte correlação desses indicadores com desigualdade de renda e morte por doenças coronárias e neoplasia, bem como mortalidade infantil (KAWACHI e outros, 1997).

Os exemplos no campo das organizações são também múltiplos. É o caso de Lang (2004), que relacionou capital social com conhecimento organizacional. Tomando o primeiro como relativo às redes e às instituições, Spence e Schmidpeter (2003) descobriram que o investimento de pequenas e médias empresas em capital social influencia o sucesso nos negócios e, ao estimular a cultura de colaboração, contribui para a sociedade como um todo.

Essa variedade de aplicações parece comprovar Portes (1998, p. 2), para quem: "social capital has evolved into something of a cure-all for the maladies affecting society 
at home and abroad", reclamando que capital social vem sendo utilizado em tantos eventos e em tão diferentes contextos que está perdendo o significado que o diferenciaria.

Mesmo com esse largo espectro de aplicação, ou até mesmo devido a ele (VAN DETH, 2003), não se consolidou uma definição única de capital social. O conceito é tão evasivo que cada autor é premido pela necessidade de apresentar o significado que pretende trabalhar (STONE e HUGHES, 2002), o que se condiciona pelo nível de análise em questão (CHIESI, 2007; VAN OORSCHOT, ARTS e GELISSEN, 2006). No nível micro, ligado às teorias da escolha racional e das trocas sociais, capital social seria um recurso a ser apropriado, tal como nos trabalhos de Lin (1999). No nível macro, se concebe capital social como parte da cultura compartilhada, como em Putnam (1995). Então, a primeira questão a ser resolvida seria se está sendo tratado o capital social individual ou coletivo (INKELES, 2000). Ainda assim, capital social pode ser relativo ao indivíduo, ao grupo informal, à organização, à comunidade, ao grupo étnico e mesmo à nação (BANKSTON III e ZHOU, 2002).

De tal forma que, já nesse ponto, admite-se como oportuno apontar que essa investigação aproxima-se da visão micro (capital social individual), centrada no indivíduopesquisador quando se estuda como esse agente amealha os recursos distribuídos pelo consórcio. Todavia, ao praticar a sua agência, o pesquisador de café não ignora que o montante a ser distribuído depende da legitimidade obtida pelo consórcio frente aos entes financiadores, por sua vez dependente da qualidade do trabalho do conjunto, alicerçado em confiança entre os parceiros, criado ao longo do tempo pelas interações nos projetos, nas reuniões e na coordenação de atividades da rede (capital social coletivo).

Já a questão de mensuração de capital social também tem atraído a atenção de um grupo de pesquisadores (entre eles: DEVINE e ROBERTS, 2003; INKELES, 2000; NARAYAN e CASSIDY, 2001; SNIJDERS, 1999; VAN DER GAAG e SNIJDERS, 2005; VAN DETH, 2003).

Tomadas em seu conjunto, as propostas para mensurar capital social, grosso modo, estão próximas entre si. Como esperado, são estudos quantitativos, causais, de matiz positivista, onde o capital social é ora tomado como variável dependente ou, na maior parte das vezes na literatura considerada, como variável independente. No primeiro caso, o foco estaria em analisar os determinantes do capital social. Quando este é a variável independente, procura-se correlacioná-lo com algum efeito (bem-estar, criminalidade, aprendizagem, desenvolvimento) e assim assinalar a validade da métrica proposta. Para implementar a investigação, os autores criam a sua definição particular de capital social. Então, defendem proxi (coesão social, participação pública, volume e diversidade da rede de contatos e outros) aquilatadas em questionários estruturados, fiando-se nas declarações, frequentemente opinativas, dos respondentes.

Ao se propor relações causais envolvendo capital social, é azado chamar a atenção para a homofilia. Mouw (2006), ao se voltar para o que chamou capital social em redes (aqui: características e recursos de amigos e conhecidos capazes de produzir resultados para o indivíduo), intentou diferenciar os efeitos do capital social daqueles propiciados pela aplicação do princípio da homofilia, pelo qual pessoas tenderiam a escolher como amigos pessoas que são similares a elas. O trabalho de Mouw (2006) serve de alerta para a possibilidade da atuação de variável não observada, risco que deve ser delimitado nos procedimentos metodológicos. Outras falhas, agora econométricas, na literatura empírica de capital social, são assinaladas por Durlauf (2002), que chega a recomendar a experimentação frente a algumas correlações apresentadas nesses trabalhos, como comprovação da eficácia do construto.

É sobre tais bases e cuidados que se sustenta o método empregado na investigação, detalhado a seguir.

\section{MÉTODO}

O ponto inicial para analisar o consórcio foi tomar como fração atômica do estudo as ligações que os pesquisadores estabelecem entre si e o padrão (que dá uma idéia de regularidade) dessas ligações, submetidas e condicionadas pelo arranjo institucional vigente nas redes colaborativas de pesquisa no Brasil, em geral - e no consórcio, especificamente. A partir daí, a pesquisa seguiu o curso da lógica hipotético-dedutiva, lançando mão de modelo relacional entre elementos do construto do capital social. Buscouse, através de técnicas como a sociometria, compor um retrato das ligações empreendidas pelos agentes e, através da análise multivariada, estabelecer correlações relevantes. Foram empregados métodos de pesquisa documental, bibliográfica, survey e de estudo de caso, com o predomínio do corte transversal no tempo. A unidade de análise foi o CBP\&D/Café. Quanto à unidade de observação, os focos foram os pesquisadores (e especificamente dentre eles, os responsáveis pelos projetos e subprojetos) e as entidades de pesquisa em relação ao consórcio.

\section{Hipóteses de trabalho}

Foi adotada a definição de Lin (1999) para capital social: investimentos em relações sociais em busca de um retorno. 
Parte-se do ponto de vista de que as pessoas se relacionam para ter acesso aos recursos do grupo. Esses recursos (1) facilitam o fluxo de informações sobre oportunidades e escolhas, reduzindo o custo das transações; (2) permitem exercer influência; (3) permitem o reconhecimento das credenciais sociais do agente; e (4) reforçam a identidade do agente como membro do grupo e portanto concedelhe acesso a seus recursos. Daí, para a medição do capital social do agente na rede subjacente ao CBP\&D/Café, partiu-se das seguintes hipóteses:

H1 - O capital social do agente é função da centralidade de sua organização na rede. Quanto mais central a organização, maior o capital social do agente. Aqui, o agente se beneficia dos créditos concedidos à sua organização. H2 - O capital social do agente está ligado ao seu prestígio junto a seus pares. Quanto maior o prestígio, maior o capital social - o agente se beneficia da reputação que lhe é conferida pelos demais membros da rede.

H3 - O capital social do agente é tanto maior quanto maior for percebido o grau de suas credenciais acadêmicas. H4 - O capital social do agente é ampliado pela sua participação nas instâncias deliberativas e decisórias da rede. Participar desses órgãos confere ao agente acesso a informações privilegiadas e valiosas e a oportunidade de praticar a agência, direcionando as decisões à sua conveniência. H5 - O capital social do agente é acrescido à medida que ele participa de mais ações promovidas pela rede. Participar de projetos confere ao agente visibilidade e estende o campo de suas interações.

Assim, o capital social (CS) seria definido como decorrente de cinco variáveis; de $\mathrm{H} 1$ : o capital organizacional; de $\mathrm{H} 2$ : o capital em prestígio; de H3: o capital acadêmico; de H4: o capital em coordenação; e de H5: o capital empreendedor. A definição operacional de tais construtos é da forma:

a) Capital organizacional ( $\mathrm{CO}$ ): é atinente à média aritmética da centralidade obtida pela entidade do agente em eventos na rede. Assim, CO foi obtido pela média da centralidade (closeness centrality, software PAJEK) das autorias do Primeiro (de 2000) e do Quinto Seminário de Pesquisa do Café (de 2007), ambos patrocinado, pelo consórcio e da centralidade das ligações entre as entidades em projetos de R\&D financiados pelo consórcio, de 2002 a 2006. Essa média foi a seguir convertida em uma escala de valor máximo igual a 4 (procedimento que foi mantido como padrão também nas outras parcelas do capital social);

b) Capital em prestígio (CP): é atinente à centralidade do agente derivada de primeira e segunda opção de seus pares na rede. Dessa forma, CP foi obtido pelo indicador authority weight (software PAJEK) derivado do sociograma das ligações construídas a partir das indicações de parceiros preferenciais;

c) Capital acadêmico (CA): é atinente às credenciais acadêmicas do agente. CA foi apurado considerando a titulação máxima e a eventual detenção da Bolsa de Produtividade do $\mathrm{CNPq}$, da forma: Graduado $\mathrm{CA}=0$; Especialista $\mathrm{CA}=1,0$; Mestre $\mathrm{CA}=2,0$; Doutor $\mathrm{CA}=$ 3,0 , Doutor com bolsa $2=3,2$; Doutor com bolsa $1 \mathrm{D}$ $=3,4$; Doutor com bolsa $1 \mathrm{C}=3,6$; Doutor com bolsa $1 \mathrm{~B}=3,8$; Doutor com bolsa $1 \mathrm{~A}=4,0$;

d) Capital em coordenação (CC): é atinente ao volume histórico de participações do agente em órgão de gestão da rede, ponderado pela importância relativa do órgão. Os fatores de ponderação advieram de sugestões de agentes entrevistados;

e) Capital empreendedor (CE): é atinente ao volume acumulado de participações - como responsável pelo projeto, como membro da equipe, como consultor, como colaborador - do agente em projetos da rede, ponderado pela importância relativa de cada participação. CE foi apurado computando o volume de participação em subprojetos, acumulado entre 1997 e 2006. Foram atribuídos pesos às categorias de participação: Colaborador (peso 0,1); Consultor (peso 0,1); Membro (peso 0,3); e Responsável (peso 0,5).

Assim, teria um volume maior de capital social aquele agente que trabalhasse para uma entidade central na rede; que fosse reconhecido por uma significativa porção de seus pares como um "sócio" preferencial; que tivesse atingido o maior grau relativo de educação e experiência e participado de um maior número de comissões importantes e de projetos da rede. Em oposição, seria pobre em capital social aquele agente de uma organização periférica, ignorado pelos pares, com pouca experiência e escolaridade (relativas), que não tivesse conseguido (ou pretendido) assento nos fóruns relevantes e que tivesse pequena participação nos projetos.

Há de se considerar ainda a eventual interdependência entre as variáveis CO, CP, CA, CC e CE no que é a sexta hipótese da pesquisa.

H6 - (Desdobrada em H6a a H6j) Existe uma relação de interdependência entre os fatores do capital social; pois, na prática, se espera que os cargos de gestão da rede (por exemplo) sejam ocupados por representantes de elevado capital acadêmico das entidades mais centrais, o que lhes confere maior prestígio, que lhes leva a serem convida- 
dos para mais projetos, em um circuito totalmente emaranhado, onde cada parcela do capital social se reforça mutuamente.

Finalmente, o capital social para ser mensurado requer mais uma hipótese:

H7 - O volume de recursos da rede gerido pelo agente é determinado pelo seu capital social. Quanto maior este for, ,maior será o valor das verbas administradas por ele.

O capital social age como uma variável que liga os capitais básicos (organizacional, em prestígio, acadêmico, em coordenação e empreendedor) à obtenção de recursos (aprovação de projetos de pesquisa e desenvolvimento).

$\mathrm{Na}$ forma matricial, os desdobramentos hipotéticos assumem a forma apresentada no Quadro 1.

\section{Implementação}

A pesquisa teve três fases. Na preparação, empregou-se a análise documental do material encontrado disponível sobre o consórcio. Simultaneamente, analisou-se um banco de dados com informações sobre os projetos financiados pelo consórcio. Em paralelo, foram construídos sociogramas de coautorias de artigos científicos apresentados em eventos (simpósios) patrocinados pelo consórcio. $\mathrm{Na}$ segunda fase, foram analisadas as transcrições de 39 entrevistas em profundidade com pessoas-chaves de seis entidades principais, identificadas na primeira fase. Finalmente, acrescentou-se ao banco de dados as informações obtidas em uma survey aplicada junto aos responsáveis pelos subprojetos. A pesquisa iniciou-se no começo de 2007; as entrevistas foram realizadas entre setembro de $2007 \mathrm{e}$ fevereiro de 2008, quando também foi aplicada a survey.

O questionário, totalmente estruturado e apenas com opções fechadas, foi composto de 12 conjuntos de questões. As primeiras três questões tiveram objetivos "demográficos". Logo a seguir, perguntou-se sobre as características mais significativas da pesquisa mais expressiva do pesquisador. A questão cinco pediu ao respondente que encaixasse a sua visão sobre o consórcio em 12 pares de categorias, à semelhança da Escala de Diferenciação Semântica de Osgood. Já a questão seis pediu a indicação de dois pesquisadores que o respondente mais provavelmente teria preferência para uma parceria dentro de um projeto a ser submetido à apreciação do consórcio. O objetivo foi montar um sociograma que indicasse o capital de prestígio dos agentes e confirmar a centralidade da rede de coautorias. A questão sete referia-se à motivação para as ligações entre pesquisadores. A questão oito prestou-se a inferir o grau de conservadorismo das ligações; enquanto a questão doze se remetia a indagar pelos resultados das ligações (mais precisamente, da participação em projetos do consórcio). A questão nove pedia aos pesquisadores para indicar o seu grau de concordância (de baixa a alta) frente a 26 afirmações em uma escala tipo Likert de sete pontos, com a opção "não sei". As questões dez e onze remetem-se aos critérios de julgamento das propostas relevante em um consórcio sustentado pelo financiamento de projetos.

A população de pesquisa foi definida como composta pelos pesquisadores responsáveis por subprojetos contratados entre 1997 e 2006. Dessa forma, a população somou 397 elementos. Destes, 236 responderam ao questionário. Esse número é superior ao mínimo objetivado (200) e correspondem a $59 \%$ da população, mas que administraram $70 \%$ das verbas destinada a P\&D (VerbaPD). Os pesquisadores restantes foram enquadrados em "inacessíveis" - 31 pesquisadores, $8 \%$ da população; "recusantes" - 29 pesquisadores, 7\% da população; e "omissos"

Quadro 1 - Hipóteses de pesquisas: correlações esperadas (todas diretas)

\begin{tabular}{|c|c|c|c|c|c|c|c|}
\hline & $\mathrm{CO}$ & $\mathrm{CP}$ & CA & CC & CE & CS & VERBA PD \\
\hline $\mathrm{CO}$ & & $\mathrm{H} 6 \mathrm{a}$ & $\mathrm{H} 6 \mathrm{~b}$ & $\mathrm{H} 6 \mathrm{c}$ & $\mathrm{H} 6 \mathrm{~d}$ & $\mathrm{H} 1$ & \\
\hline $\mathrm{CP}$ & & & $\mathrm{H} 6 \mathrm{e}$ & $\mathrm{H} 6 \mathrm{f}$ & $\mathrm{H} 6 \mathrm{~g}$ & $\mathrm{H} 2$ & \\
\hline $\mathrm{CA}$ & & & & $\mathrm{H} 6 \mathrm{~h}$ & $\mathrm{H} 6 \mathrm{i}$ & H3 & \\
\hline$C C$ & & & & & $\mathrm{H} 6 \mathrm{j}$ & $\mathrm{H} 4$ & \\
\hline CE & & & & & & $\mathrm{H} 5$ & \\
\hline CS & & & & & & & $\mathrm{H} 7$ \\
\hline
\end{tabular}


- 105 pesquisadores, 26\% da população. Cabe observar que entre os 31 inacessíveis, foram encontrados casos de aposentadorias e mesmo de falecimento, o que era esperado, considerando o hiato de dez anos entre os primeiros projetos e o período de aplicação do questionário. Já a maior fração dos 29 recusantes justificou-se alegando afastamento da pesquisa do café.

Ao se investigar correlação entre o grupo "respondente" (= participante) e o grupo "não respondente" (= inacessível + recusante + omisso) e algumas variáveis, não se verificou tendência com relevância estatística (teste Phi e Cramer's) quanto a sexo, entidade e titulação-experiência. No entanto, o mesmo teste de significância indicou alguma relação, ainda que fraca, para CC, CE, e CP. A amostra resultante foi ligeiramente concentrada naqueles pesquisadores de mais alto CC, CE e CP. Isso já seria o suficiente para questionar uma eventual pretensão de aleatoriedade da amostra.

\section{RESULTADOS}

O trabalho gerou uma massa considerável de resultados, incluindo sociogramas de coautorias e uma descrição detalhada das estratégias de inserção dos pesquisadores na rede. Para efeito deste artigo considerou-se suficiente e necessária uma descrição sociométrica do consórcio como contexto para o teste de hipótese, apresentado logo após a descrição da rede de pesquisadores.

\section{Rede de pesquisadores}

Foram construídos os sociogramas derivados das escolhas preferenciais dos respondentes do questionário. Cada respondente que indicou seus parceiros preferenciais é um vértice, que "dispara" um arco na direção de suas indicações. Com isso é possível indicar o grau de autoridade - authority weight - de um vértice (medida da proeminência de determinados vértices em directed graphs, resultante de algoritmo interativo desenvolvido por Kleinberg (1999) cuja adaptação foi incorporada ao software PAJEK; semelhante ao "grau", com a diferença de levar em conta a importância do vértice que originou a ligação: receber uma ligação é interessante, receber uma ligação de alguém importante, mais ainda).

$\mathrm{Na}$ rede, estão presentes 287 vértices, 51 a mais que o número de respondentes - uma vez que foram também indicados pesquisadores além daqueles que participaram do questionário e que faziam parte da população em estudo. Foram computadas 443 ligações. A Figura 1 reproduz esse sociograma. Antes de tomá-lo como evidência do estudo, foi necessário testar a hipótese de que tal estrutura poderia advir de mero acaso. Para se verificar tal possibilidade, Nooy, Mrvar e Batagelj (2005) recomendam fazer um censo do tipo e frequência das triads presentes (ligações, ou ausência delas, tomando três vértices da rede) e compará-lo com o mesmo censo de outra rede, com mesmas características (número de vértices e de ligações), gerada aleatoriamente. O software testa a hipótese nula, que a rede de pesquisadores é aleatória. Aplicando a técnica, o resultado é tal que se afirma (1) que a rede de pesquisadores do consórcio (escolhas preferenciais), provavelmente, não deve ser fruto do acaso, isso ao nível de significância estatística de 0,001 e, portanto, (2) os dados estruturais obtidos permanecem válidos, até prova em contrário.

Na Figura 1, os círculos representam os pesquisadores e os arcos (segmentos de reta) as ligações preferencias indicadas pelo pesquisador/vértice. É possível inferir uma distribuição irregular de prestígio entre os pesquisadores, comprovada ao se fazer um histograma derivado do sociograma. Assim, comprova-se que o pesquisador mais pestigiado recebeu 11 indicações, seguido por outros dois cientistas mais cotados, que receberam 10 indicações dos colegas; por outro lado, 105 pesquisadores não foram escolhidos nem uma única vez pelos seus pares. Enquanto existe um grupo de 230 pesquisadores que receberam duas ou menos indicações e que poderia assim ser considerado como de menor prestígio, há um grupo mais distinto, de 25 pesquisadores $\sim 10 \%$, que receberam de cinco a onze indicações, que seriam candidatos ao título de maior prestígio.

Adicionalmente, no canto inferior direito da Figura 1, é possível indicar um grupo de pesquisadores que estão ligados ao grupo maior por apenas algumas ligações. $\mathrm{O}$ rompimento dessas ligações isolaria o grupo - portanto, existem ali vértices fazendo pontes e, daí, com grau menor de redundância em suas ligações, o que para Burt (2004, 2005) seria uma indicação de agentes com maior Capital Social. E existem ainda uns poucos pesquisadores que não se conectam ao grupo. Essas exceções foram provocadas por quatro pesquisadores respondentes que não quiseram fazer suas indicações entre aquelas oferecidas e por três respondentes que escolheram não respondentes que não foram indicados por outras pessoas da rede.

Ainda, ao se relacionar as verbas de pesquisa, a posição estrutural (Figura 1) e o prestígio, revela-se uma estrutura cuja coluna é suportada por um conjunto de 20 elementos de alto prestígio (e de grande captação de recursos, 25\% da verba total para P\&D) altamente conectados entre si (grupo bem coeso: das 20 pessoas de maior capital em 
prestígio, 16 estão diretamente associadas entre si por escolhas preferenciais). Esse grupo se conecta a 95\% da rede através de ligações diretas e indiretas (mesmo dispensando caminhos longos, acima de três intermediações, o grupo central se mantém conectado a $80 \%$ da rede). Por último, os elementos de tal grupo coeso são centrais e distam de posições que poderiam se configurar em pontes, de tal forma que, mesmo removendo o grupo (e suas ligações) da rede, apenas $7 \%$ dos pesquisadores perderiam a sua conexão com a rede.

\section{Capital social no consórcio}

As hipóteses relativas ao capital social são agora retomadas, dentro do contexto traçado no item precedente.

Ao longo de sua existência, o consórcio referendou e reproduziu um quantum diferenciado de prestígio. Consolidou-se um grupo de entidades, não maior que 10 , que são aquinhoadas com a maior parte dos recursos e têm seus pesquisadores (em torno de 60) ocupando os cargos na estrutura burocrática do consórcio

Para Burt $(2004,2005)$, dentro de sua teoria de pontes sobre vazios estruturais, o capital social é indicado pelo grau de redundância das ligações de cada vértice. Quanto menor esse grau, maior a probabilidade que o vértice teria para amealhar os benefícios da rede.

O benefício disputado no consórcio é o financiamento para a pesquisa e eventualmente, reputação. Acesso a novos conhecimentos e desenvolvimento da rede de parcerias não são benefícios cujo consumo impedem o outro de também fazê-lo (pelo contrário, eles são expandidos com o concurso de outros, no que seria um capital social coletivo).

Portanto, o capital social deveria estar relacionado com o valor da verba capturado pelo pesquisador. Quanto maior seu capital social, maior a chance de ser convidado para a proposição de um projeto e maior a chance de conseguir aprovação dos projetos Assim: CS VerbaPD (montante de financiamento angariado pelo agente para projetos de pesquisa).

Para testar a hipótese de Burt, basta relacionar o grau de redundância (aggregate constraint) na rede formada por ligações preferenciais com VerbaPD e verificar o nível de significância $p$ e $r^{2}$. Ao fazê-lo, constata-se que $r^{2}$ é tão pequeno $(=0,07)$ que se pode afirmar que a hipótese

\section{Figura 1 - Sociograma da escolha preferencial dos pesquisadores}

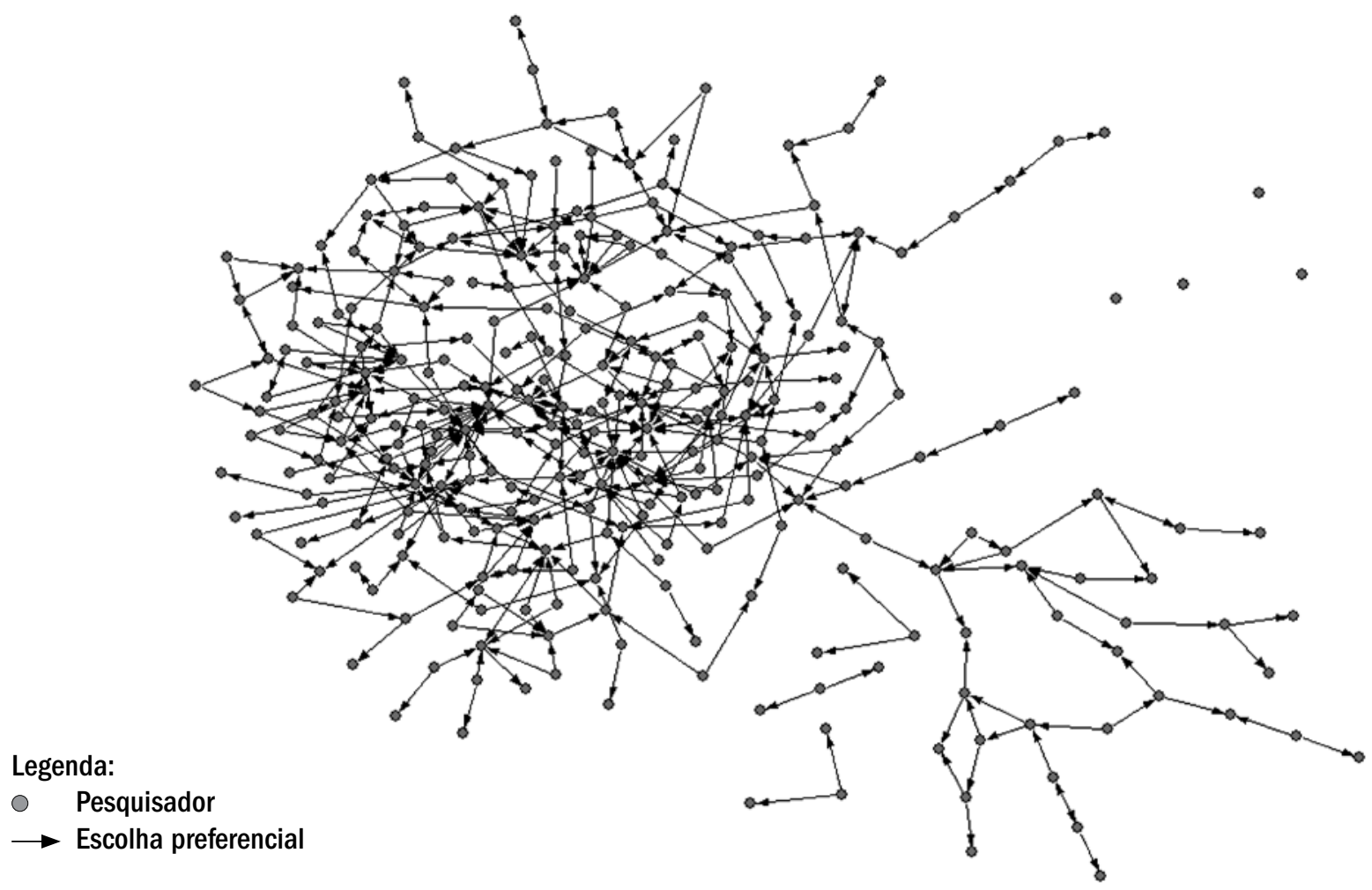


de Burt deve ser abandonada, mesmo que $p=0,000$. Em seu lugar, com $r^{2}$ de 0,312 para $p=0,000$ (superior, mais ainda insuficiente), foi tomado como indicador o grau de importância (authority weight) do vértice. Dessa forma, o authority weight surge como uma indicação mais interessante para o capital em prestígio.

O próximo passo foi correlacionar os diversos capitais, conforme apresentado na Tabela 1. Com esse quadro é possível testar algumas das hipóteses de trabalho. Assim, para o nível de significância bicaudal de 0,01, afirma-se que foram encontradas correlação de CO com CA e CE; de CP com CC e CE; e de CC com CE. Digno de ressalva é o papel de CA. Pelos dados, o fato de ser doutor com bolsa de produtividade não confere uma distinção significativa quanto ao prestígio, à participação em projetos e à participação em órgãos do Consórcio. A diferença de CA somente é significativa entre as entidades de maior centralidade frente às de menor centralidade (indicado por $\mathrm{CO}$ ).

Outro aspecto que mereceu consideração foi a oportunidade de se empregar a abordagem multinível, remetendo
CO para o nível organizacional, enquanto CC, CE, CP e CA foram tomados como da ordem do agente. Nessa situação, por exemplo, foi estudado o efeito de se pertencer a uma organização central sobre $\mathrm{CP}$, seguindo os passos de Lazega e outros (2008). Ao final, concluiu-se que mesmo pertencendo a uma organização menor - little pond, no dizer de Lazega e outros (2008) - o pesquisador de mais prestígio - big fish - consegue se destacar na captação de verbas do Consórcio.

A próxima etapa foi testar diversas possibilidades de regressão (no caso linear) que ligasse as variáveis tomadas como independentes e a VerbaPD, fazendo-o igual à CS. Testou-se regressão empregando as cinco variáveis (CA, $\mathrm{CO}, \mathrm{CC}, \mathrm{CP}$ e CE), quatro delas (CO, CC, CP e CE) e três delas ( $\mathrm{CP}, \mathrm{CE}$ e $\mathrm{CC}$ ). Elas foram desprezadas, na medida em que o erro padrão de algum coeficiente indicava nível de significância acima daquele tomado como aceitável (máximo de 0,05). Ao se utilizar apenas CE e CP, a questão deixou de existir, obtendo-se $r^{2}$ ajustado de 0,473 e nível de significância 0,000, tal como na Equação 1 . É pertinente ressaltar que $\mathrm{CE}$ e CP estão correlacionados

Tabela 1 - Teste de correlação (CO, CA, CE, CC, CP e VerbaPD)

\begin{tabular}{|c|c|c|c|c|c|c|}
\hline & & CC & CO & CA & CE & $\mathrm{CP}$ \\
\hline \multirow[t]{3}{*}{$\mathrm{CO}$} & $r$ & 0.013 & & & & \\
\hline & $\mathrm{p}$ & 0.803 & & & & \\
\hline & $\mathrm{N}$ & 388 & & & & \\
\hline \multirow[t]{3}{*}{$\mathrm{CA}$} & $r$ & -0.004 &, $354(* *)$ & & & \\
\hline & $p$ & 0.938 & 0.000 & & & \\
\hline & N & 359 & 368 & & & \\
\hline \multirow[t]{3}{*}{ CE } & $r$ &, $513(* *)$ &, $200(* *)$ & 0.099 & & \\
\hline & $\mathrm{p}$ & 0.000 & 0.000 & 0.061 & & \\
\hline & $N$ & 388 & 388 & 359 & & \\
\hline \multirow[t]{3}{*}{$\mathrm{CP}$} & $r$ &, $379(* *)$ & 0.086 &, $103\left(^{*}\right)$ &, $464(* *)$ & \\
\hline & $\mathrm{p}$ & 0.000 & 0.086 & 0.049 & 0.000 & \\
\hline & $\mathrm{N}$ & 388 & 397 & 368 & 388 & \\
\hline \multirow[t]{3}{*}{ VerbaPD } & $r$ &, $414(* *)$ & 0.073 & 0.082 &, $616(* *)$ &, $561(* *)$ \\
\hline & $\mathrm{p}$ & 0.000 & 0.154 & 0.122 & 0.000 & 0.000 \\
\hline & $\mathrm{N}$ & 388 & 388 & 359 & 388 & 388 \\
\hline
\end{tabular}

r: coef. de Pearson; p: nível de significância bicaudal; N: número de casos

** Correlação é significativa ao nível de 0,01(bicaudal).

* Correlação é significativa ao nível de 0,05 (bicaudal). 
entre si, o que traz consigo o problema da colinearidade. Haveria solução estatística para essa questão - mas ela não foi explorada, e assim a Equação 1 deve ser tomada com essa ressalva.

\begin{tabular}{|lrccc|}
\hline $\mathrm{CS}=$ & $-0,014$ & $+2,453 \mathrm{CE}$ & $+2,853 \mathrm{CP}$ & \\
Erro padrão: & 0,134 & 0,225 & 0,340 & \\
Estatística $t:$ & $-0,101$ & 10,884 & 8,399 & (Equação 1) \\
Sig.: & 0,920 & 0,000 & 0,000 & \\
\hline
\end{tabular}

Para lidar com a hipótese H7, foi admitido o capital social como aquela combinação matemática de CP e CE expressa na Equação 1. Apurada dessa forma, a estabilidade da correlação (CS \& VerbaPD) foi testada, seccionando o banco de dados por período (primeiros 5 anos e últimos 5 anos) e por montante de volume de recursos amealhados pelos pesquisadores ( 80 maiores VerbaPD, 160 maiores VerbaPD). Em todos os testes, o capital social teve uma performance próxima daquela obtida com o banco de dados completo.

Contudo, salienta-se que a prova mais indicada, na qual seria aplicada a Equação 1 em novos dados acumulados a partir daqueles que lhe deram origem, está ainda aguardando o acúmulo necessário de novas evidências. Mas, adianta-se, não foram encontrados, até o momento, fatos que levem à refutação de H7. Pelo contrário, se Capital Social é relacionado com a apropriação "excludente" de benefícios da rede e se o maior benefício percebido pelos pesquisadores é o financiamento de seus projetos, então o capital social estaria relacionado com a VerbaPD, ainda mais porque seus constituintes (CP e $\mathrm{CE}$ ) o estariam. Alguém poderia ver nessa argumentação o que Portes (1998, p. 19-20) aponta como circularidade lógica de alguns conceitos de capital social: este seria simultaneamente causa e efeito - produziria resultados positivos e a sua existência seria inferida desses mesmos resultados. Para lidar com essa questão, evidenciando o efeito do capital social, deve-se tomar em consideração que pelo menos metade dos pesquisadores que participaram do questionário admite um comportamento "político" do consórcio que o afasta de decisões meramente meritocráticas. Se o $\mathrm{CBP} \& \mathrm{D} / \mathrm{Café} \mathrm{seguisse} \mathrm{os} \mathrm{ditames} \mathrm{meritocráticos} \mathrm{à} \mathrm{risca,}$ as propostas escolhidas seriam aquelas que melhor tratassem os problemas prioritários da cafeicultura brasileira, submetidas por aqueles que possuíssem capacidade para executá-las. Essa não é percepção hegemônica: foram diversos os depoimentos que apontaram outros mecanismos atuando. Tanto que 58\% dos respondentes do questionário demonstraram algum grau de concordância com a afirmação: "A melhor forma de se conseguir a aprovação de um projeto dentro do consórcio é se unir a entidades e a pesquisadores com alta reputação."

Os pesquisadores que participam dos órgãos do consórcio são eleitos entre os pares e é esperado que a escolha recaia naqueles de maior prestígio, o que foi confirmado pela correlação entre CP e CC. Participar de tais órgãos permite a esses pesquisadores uma articulação mais informada e com maiores chances de sucesso. Por outro lado, as pessoas com maior possibilidade de serem convidadas para participar de projetos são também aqueles de maior prestígio (correlação entre $\mathrm{CP}$ e $\mathrm{CE}$ ), que podem assim escolher a sua participação entre diversas oportunidades de trabalho. Essa visibilidade deve repercutir positivamente na distribuição das verbas. O mesmo não pode ser dito do capital acadêmico: ser reconhecido como doutor com pontuação máxima não foi encontrado como diferencial na alocação dos recursos do consórcio.

Havendo correlação, como se comprovaria a casualidade? Ora, o consórcio existia há apenas dez anos na época da investigação, mas a pesquisa do café no Brasil existe desde muito antes. O gradiente de prestígio entre os pesquisadores já estava presente na própria criação do Consórcio, e foram justamente aqueles pesquisadores de maior prestígio, naquelas entidades tidas como mais importantes, que foram os responsáveis por dar forma ao consórcio e empreender as primeiras pesquisas sob o seu manto, como comprovado nas entrevistas. Quanto mais pesquisas eles empreendiam, mais reforçadas se viam as respectivas reputações, mais eram considerados para cargos e maiores eram as oportunidades de participações em novos projetos. Tratar-se-ia de um constituinte do capital social, reforçando o outro e consolidando uma estrutura diferenciada, típica quando se trata de capital: poucos com muito, muitos com pouco. No caso do consórcio, 60 com elevado capital social, 1.300 com pouco.

\section{CONCLUSÃO}

As redes colaborativas de pesquisas têm assumido papel relevante nas políticas públicas de P\&D. Esse arranjo é agora assumido como o mais apropriado, como mecanismo congregador das competências e capacidades requeridas para lidar com problemas complexos, que requeiram a transdisciplinaridade. Os pesquisadores são instados pelos organismos de fomento a cooperar. Eles o fazem, sob o império de diversas lógicas, incluindo a proximidade, a história de cooperações passadas, a proximidade 
física, a amizade, a oportunidade e a necessidade. Mesmo quando não admitido, a cooperação é facilitada ou inibida pelo quantum de capital social presente entre os agentes.

O capital social, tal como definido e mensurado nas seções precedentes, mostrou-se com razoável poder explicativo $\left(r^{2}=0,473\right.$ para $\left.p=0,000\right)$ para a questão relativa à apropriação de verbas do consórcio - e isso traz algumas repercussões para aqueles que participam da gestão de arranjos semelhantes. Desconsiderar o capital social seria o mesmo que negar importância às ligações entre pessoas, de onde ele se origina - o que traria um significativo potencial de risco à gestão das redes e aos propósitos a que elas se destinam. O capital social não deve ser tido como um intruso mal vindo: ele seria inerente e, pelo menos no caso considerado, antecedente ao próprio arranjo.

Sopese o maior constituinte do capital social: o capital em prestígio. Este foi encontrado simplesmente pedindo aos agentes da rede indicação de seus parceiros preferenciais. Evidenciou-se dessa métrica um perfil de distribuição próximo da lei de Pareto, que antecipava e correlacionava com a distribuição desigual, concentrada, de verbas do consórcio.

A observação do sociograma de escolhas preferenciais permite ratificar algumas das proposições de Newman (2001, 2004): (a) um pequeno número de pesquisadores tem um grande número de parceiros, enquanto a maioria tem um número significativamente menor; (b) normalmente, é pequena a distância média entre os pesquisadores, medida pelo número de ligações necessárias para ir de um ponto a outro da rede; (c) o menor caminho entre dois pontos normalmente passa por alguns poucos pesquisadores "mais bem" conectados; (d) a maior parte dos pesquisadores estão de alguma forma conectados entre si; e (e) as redes colaborativas são altamente conectadas e não correm riscos imediatos de fragmentação.

A utilização das relações de coautoria é mais comum em pesquisas relativas a redes colaborativas de pesquisas. Apesar de também aplicada durante a investigação, concedeu-se primazia a análise das opções preferenciais dos pesquisadores. Espera-se assim ter conferido algum diferencial à investigação.

Ressalta-se que foram discutidos os efeitos do capital social, mas pouco ou nada dito sobre os fatores que levam as pessoas a adquirir um maior quantum de capital social. Alguns possíveis condicionantes foram testados, mas considerados irrelevantes, o que exigirá esforços adicionais, em nova fase da pesquisa - que poderia incluir ainda questões caras ao capital social coletivo, voltado ao estabelecimento e à manutenção da confiança entre os pesquisadores e o efeito dela no resultado almejado pelo consórcio, de aumentar a competitividade do agronegócio café do Brasil.

Por fim, além das limitações já citadas, é ainda adequado acrescentar que, embora o método empregado para propor a equação de capital social possa ser replicado em outras redes colaborativas, a equação resultante se restringe ao consórcio, no espaço temporal considerado.

\section{REFERÊNCIAS}

BANKSTON III, C. L; ZHOU, M. Social capital as process: the meanings and problems of a theoretical metaphor. Sociological Inquiry, v. 72, n. 2, p. $285-317,2002$.

BARABÁSI, A. L; JEONG, H; NÉDA, Z; RAVASZ, E; SCHUBERT, A; VICSEK, T. Evolution of the social network of scientific collaborations. Physica A, v. 311, n.3-4, p. 590-614, 2002

BATT, P. J. Building social capital in networks. Industrial Marketing Management, v. 37, n.5, p. 487-449, 2008.

BOARDMAN, C; CORLEY, E. A. P. University research centers and the composition of research collaborations. Research Policy, v. 37, n.5, p. 900-913, 2008

BOZEMAN, B; CORLEY, E. Scientists' collaboration strategies: implications for scientific and technical human capital. Research Policy, v. 33, n. 4, p. 599-616, 2004

BURT, R. S. Structural holes and good ideas. American Journal of Sociology, v. 110 , n. 2, p. 349-399, 2004

BURT, R. S. Il capitale sociale dei buchi strutturali. Sociologia e Politiche Sociale, v. 8, n. 1, p. 49-90, 2005.

CATTELL, V. Poor people, poor places, and poor health: the mediating role of social networks and social capital. Social Science E Medicine, v. 52, n. 10, p. 1501-1516, 2001.

CHIESI, A. M. Measuring social capital and its effectiveness. European Sociological Review, v. 23, n. 4, p. 437-453, 2007.

CORLEY, E; BOARDMAN, P. G; BOZEMAN, B. Design and the management of multi-institutional research collaborations. Research Policy, v. 35, n. 7 p. $975-993,2006$.

DEVINE, F; ROBERTS, J. M. Alternative approaches to researching social capital. Theory and Practice, v. 6, n. 1, p. 93-100, 2003

DURLAUF, S. N. On the empirics of social capital. The Economic Journal, v. 112, n. 483, p. 459-479, 2002. 
FARREL, H; KNIGHT, J. Trust, institutions, and institutional change: industrial districts and the social capital hypothesis. Politics Society, v. 31, n. 4 , p. 537-566, 2003.

GOPEE, N. Human and social capital as facilitators of lifelong learning in nursing. Nurse Education Today, n. 22, p. 608-616, 2002.

GROOT, W; VAN DEN BRINK, H. M; VAN PRAAG, B. The compensating income variation of social capital. Social Indicators Research, v. 82, n.2, p. 189-207, 2007.

INKELES, A. Measuring social capital and its consequences. Policy Sciences, n. 33, p. 245-268, 2000.

KATZ, J. S; MARTIN, B. What is research collaboration? Research Policy, v. 29, n.1, p. 1-18, 1997.

KAWACHI, I; KENNEDY, B. P; LOCHNER, K; PROTHROW-STITH, D. Social capital, income inequality and mortality. American Journal of Public Health, v. 87, n.9, p. 1491-1498, 1997.

KENNEDY, B. P; KAWACHI, I; PROTHROW-STITH, D; LOCHNER, K; GUPTA, V. Social capital, income inequality, and firearm violent crime. Social Science and Medicine, v. 47, n. 1, p. 7-17, 1998.

KLEINBERG, J. M. Authoritatives sources in a hyperlinked environment. Journal of the Association for Computing Machinery, v. 46, n. 5, p. 604632, 1999.

KRAMER, D. B. Determinants and efficacy of social capital in lake associations. Environmental Conservation, v. 34, n. 3, p. 186-194, 2007.

KRISNA, A. Understanding, measuring and utilizing social capital. Agricultural Systems, v. 82, n.3, p. 291-305, 2004.

LANDRY, R; AMARA, N. The impact of transaction costs on the institutional structuration of collaborative academic research. Research Policy, v. 27, n. 9, p. 901-913, 1998.

LANG, J. C. Social context and social capital as enablers of knowledge integration. Journal of Knowledge Management, v. 8, n. 3, p. 89-106, 2004.

LAZEGA, E; JOURDA, M. T; MOUNIER, L; STOFER, R. Catching up with big fish in the big pond? Social Networks, v.30, n. 2, p. 159-176, 2008.

LIN, N. Building a network theory of social capital. Connections, v. 22, n. 1, p. 28-51, 1999.

MANSYUR, C; AMICK, B. C; HARRIST, R. B; FRANZINI, L. Social capital, income inequality, and self-rated health in 45 countries. Science $\&$ Medicine, v.. 66, n.1, p, 43-56, 2008.
MELIN, G. Pragmatism and self-organization: research collaboration on the individual level. Research Policy, v. 29, n.1, p. 31-40, 2000.

MOUW, T. Estimanting the causal effect of social capital: a review of recent research. Annual Review of Sociology, v. 32, p. 79-102, 2006.

NARAYAN, D; CASSIDY, M. A dimensional approach to measuring social capital: development and validation of a social capital inventory. Current Sociology, v. 49, n. 2, p. 59-102, 2001

NEWMAN, M. E. J. The structure of scientific collaboration networks PNAS, v. 98, n. 2, p. 404-409, 2001

NEWMAN, M. E. J. Coauthorship networks and patterns of scientific collaboration. PNAS, v. 101, n. 1, p. 5200-5205, 2004.

NOOY, W de; MRVAR, A; BATAGELJ, V. Exploratory social network analysis with Pajek. New York: Cambridge University Press, 2005.

ONYX, J; BULLEN, P. Measuring social capital in five communities. Journal of Applied Behavioral Science, v. 36, n. 1, p. 23-42, 2000.

PORTES, A. Social capital: its origins and applications in modern sociology. Annual Review of Sociology, v. 24, p. 1-24, 1998

PUTNAM, R. D. Bowling alone: America's declining social capital. Journal of Democracy, v. 6, n. 1, p. 65-78, 1995.

RIGBY, J; EDLER, J. Peering inside research networks. Research Policy, v. 34, n.6, p. 784-794, 2005

SNIJDERS, T. A. B. Prologue to the measurement of social capital. The Tocqueville Review: La Revue Tocqueville, v. XX, n. 1, p. 27-44, 1999.

SPENCE, L. J; SCHIMIDPETER, R. SMEs, social capital and the common good. Journal of Business Ethics, v. 45, n. 1, p. 93-111, 2003.

STONE, W; HUGHES, J. Social capital: empirical meaning and measurement validity. Australian Institute of Family Studies, Research paper n. 27, 2002.

VAN DER GAAG, M; SNIJDERS, T. A. B. The resource generator: social capital quantification with concrete items. Social Networks, v. 27, n.1, p. $1-29,2005$

VAN DETH, J. W. Measuring social capital: orthodoxies and continuing controversies. Theory and Practice, v. 6, n. 1, p. 79-92, 2003.

VAN OORSCHOT, W; ARTS, W; GELISSEN, J. Social capital in Europe. Acta Sociológica, v. 49, n. 2, p. 149-167, 2006. 